\title{
ENFERMEDADES INFECCIOSAS ENDÉMICAS EN EL PERÚ TRANSMITIDAS POR DÍPTEROS HEMATÓFAGOS
}

\author{
PEORO RENGIFO GRATELLI
}

EAP DE FARMACIA Y BIOQUÍMICA DE LA UNIVERSIDAD PERUANA LOS ANDES.

\section{DESCRIPCIÓN DE LOS PRINCIPALES VECTORES DÍPTEROS EN EL PERÚ}

El orden díptera incluye muchas especies de moscas, mosquitos o zancudos, muchas de las cuales suelen ser hematófagas o no hematófagas, son muy importantes desde el punto de vista médico porque actúan como huespedes intermediarios o transmisores mecánicos de enfermedades bacterianas, virales, protozoarias y helmínticas en el ser humano. Morfológicamente los dípteros se caracterizan porque son insectos voladores que presentan el primer par de alas sumamente desarrolladas y el segundo par transformado en estructuras que participan en el equilibrio para el vuelo, denominadas "halterios». Poseen una cabeza desarrollada provista de dos ojos compuestos. Las antenas están equipadas de órganos sensoriales (2), (3). Los dípteros han modificado significativamente las partes bucales con la finalidad de adaptarlas para la alimentación de sangre, jugos de vegetales, néctar y líquidos vertidos en superficies. En la subfamilia culicidae solamente las hembras son hematófagas, los machos se alimentan de jugos vegetales. En las hembras las piezas bucales, se han modificado, las mandibulas pares en forma de estiletes, y el conducto alimenticio esta formado por labroepifaringe $e$ hipofaringe y los dientes vestigiales le permiten atravesar la piel, la dieta de sangre permite fertilizar los huevos, mediante la presencia de algún metabolito presente en la sangre, quizá la serotonina 0 adrenalina de los animales homotermos.(2), (4), (6) Se estima que entre moscas y mosquitos existen unas noventa mil especies en todo el mundo. (1)

\section{CICLO VITAL}

La mayoría de los dípteros son ovíparos, pero en algunos casos depositan larvas en diversos grados de desarrollo. Los huevos o larvas son depositados en el agua el, suelo, materia orgánicas o en la piel de vertebrados. La larva es alargada, sin patas parecida a un gusano, muy voraz y puede llevar una existencia acuática (como los zancudos: culícidos y anofélidos) o terrestre (en caso de moscas). Luego de tres a cuatro mudas, se convierte en pupa que no se alimenta y finalmente de ella brota el adulto. (5), (6)

En nuestro país destacan como vectores intermediarios:

La Familia: Culicidae

A. Subfamilia: Anophelinae Género: Anopheles

B. Subfamilia: Culicinae Género: Culex

Género: Aedes

La Familia: Psychodidae Género: Phlebotomos (5)

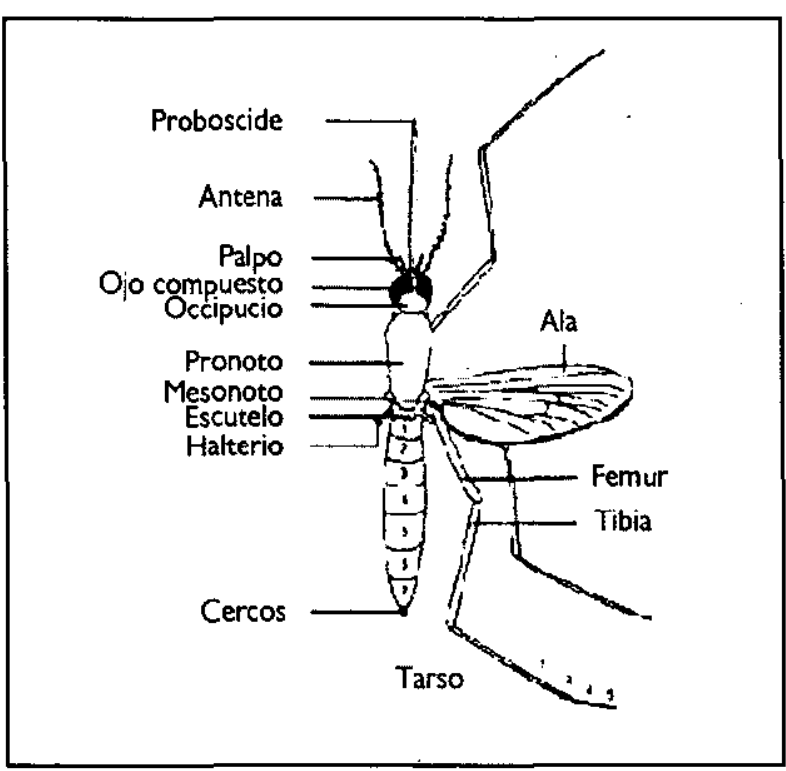

Fig. 1. Anatomía morfológica general de los Culícidos (Extraido de Miyazaki, Ichiro, p. 413, 199) 

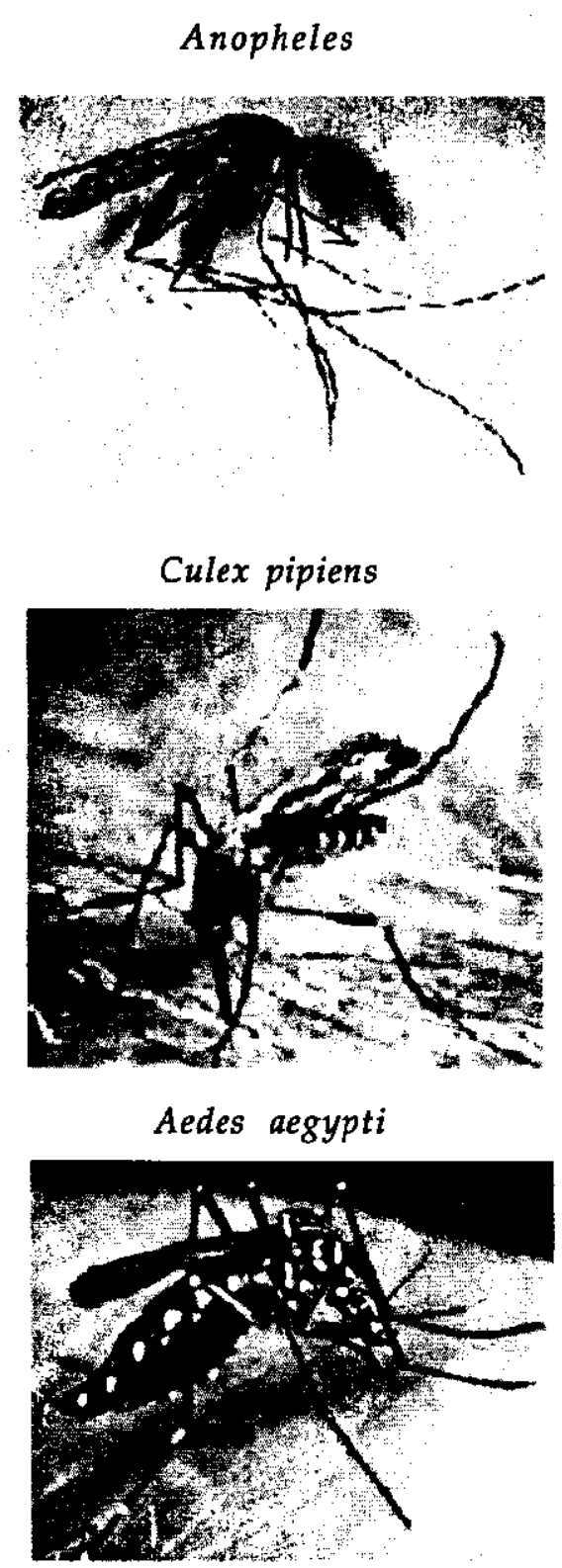

Fotografías de las diversas especies de dípteros hematófagos más comunes en el Perú. (Extraído de la Galería fotográfica de la Universidad de Iowa)

Esquema general del ciclo biológico en la familia de los culícidos

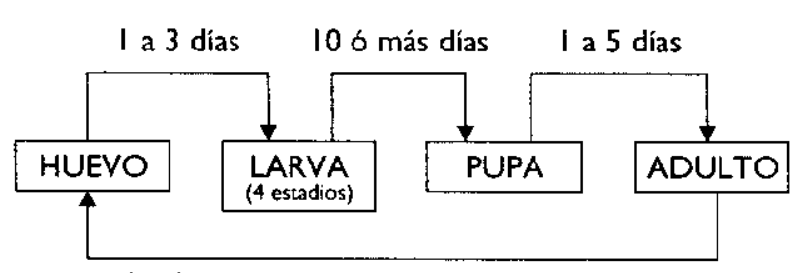

I a 2 dias después ocurre la ovipostura

\section{MECANISMO DE INFECCIÓN}

Para comprender el mecanismo de infección se requiere conocer las condiciones ambientales y hábitos en que se desenvuelve el ciclo biológico de los culícidos. Al entrar en la temporada de precipitaciones pluviales: diciembre a mayo, en la sierra y selva; y junio a noviembre, en la costa. Los culícidos despliegan vuelos prenupciales, es aquí cuando las hembras requieren de una dieta hematófaga para producir poblaciones de huevos fértiles que son depositados en diversas fuentes de agua, usualmente dulces o ligeramente salobres, idóneamente con temperaturas de 25 a $35^{\circ} \mathrm{C}$ y con mayor o menor grado de oxigenación. Anopheles es muy focalizado, entre la zona de cría y de alimentación usualmente no hay una distancia más allá de unos kilómetros. Fn el otro extremo está Aedes que puede desplazarse hasta $150 \mathrm{Km}$. para alimentarse de sangre. El requerimiento de nutrientes para el desarrollo de las larvas es múrimo. En cierta ocasión, en Pucallpa, en un depósito de agua se identificó larvas viables de Culex. Al inicio de la temporada lluviosa la biomasa de zancudos adultos se multiplica exponencialmente, entonces la hembra hematófaga al alimentarse de una persona infectada por parásitos, bacterias o virus, a su vez se infecta a nivel de las células de sus glándulas salivales o el tracto intestinal, desarrollando dentro del vector, algunos estadios del agente infeccioso. Un ciclo de desarrollo sexual complejo del protozoario Plasmodium, causante de la malaria, tiene lugar dentro del tracto intestinal del mosquito Anofeles, al que se le denomina esporogonia. Los dípteros infectados muestran unas estructuras bulbosas en el tracto intestinal cargados de las formas infectantes para el humano, denominadas esporozoitos. $\mathrm{Al}$ romperse los oocistos se liberan esporozoitos, los que al alcanzar las glándulas salivales, son inyectados junto con la saliva en la picadura a una persona sana o enferma, causándole la infección o reinfección de la malaria. En otros casos en el vector, se reproduce una población del agente etiológico viral, (no actúa como vector biológico). (1), (2), (3)

\section{ENFERMEDADES ENDÉMICAS MÁS IMPORTANTES EN EL PERÚ}

La fiebre amarilla. Es una enfermedad viral causada por un arbovirus y es transmitida por Aedes aegypti. Se caracteriza por fiebre, ictericia, insuficiencia renal y sangrado. En todo el continente americano se han notificado 2935 casos entre 1985 y 1999, con un total de 1764 muertes. Más del $80 \%$ de estos casos provinieron de Bolivia y Perú. (9) 
No existe tratamiento específico para esta enfermedad, los síntomas pueden atenuarse mediante el uso de líquidos intravenosos, transfusiones sanguíneas o diálisis en la insuficiencia renal severa. Las medidas de vacunación dos semanas antes de viajar a las zonas endémicas (zonas de ceja de selva o "rupa rupa" de los departamentos de Ayacucho, Junín, Huanuco y Ucayali) permitió rebajar el número de casos reportados de 503 -con letalidad de $38 \%$ - a 86 casos -con 34 defunciones- para el año 1996. (8)

El Dengue. El dengue es una enfermedad viral causada por un arbovirus del grupo B y es transmitida por Aedes aegypti. Esta enfermedad relativamente leve se caracteriza por fiebre, erupciones en la piel y fuertes dolores articulares y musculares. Únicamente Aedes es capaz de reproducir al virus a nivel de las glándulas salivales, convirtiéndose en vector infectivo durante toda su vida. En el Perú se produjo un brote epidémico del Dengue clásico en 1990 con un reporte de 9623 casos. Entre 1990 y 1995, se identificó el serotipo 1 del virus y entre 1996 y 2002 se identificaron el serotipo del Dengue 1 y 2 y en menor medida el serotipo4. (Reporte del Ministerio de salud, 2003). Las zonas más afectadas de esta enfermedad fueron los departamentos de Amazonas, San Martín, Loreto, Ucayali, Huánuco, entre otros.

La Malaria. Es una enfermedad producida por el protozoario Plasmodium de la clase Matigophorea, parásito de los glóbulos rojos de la sangre, se caracteriza por graves accesos de fiebre sudoración, escalofríos y anemia. Algunos epidemiólogos consideran que el ser humano ya hubiera desaparecido de los habitats tropicales y subtropicales debido a esta enfermedad, de no ser por su complicado ciclo biológico, tanto en el ser humano como en el vector el díptero hematófago: Anopheles. En el ser humano se verifica una fase de reproducción asexual del vector a nivel extraeritrocítico en el cual casi todas las formas infectivas son fagocitadas por la línea de defensa mediada por células. La más peligrosa forma de malaria, por su letalidad, es la causada por Plasmodium falciparum.

En 1998, coincidente con el último «fenómeno del niño" se registró el mayor número de casos en toda la historia de esta enfermedad en el Perú con un total de 212,642 casos. Los departamentos más afectados son: Loreto, Tumbes, Madre de Dios, Piura, San Martín, Ayacucho, Junín y Cuzco, en orden de riesgo y prevalencia. Sin embargo, debe destacarse que en dicho año incluso en Lima se registraron casos aislados. (7), (8)
La Leishmaniasis. Es una enfermedad producida por el protozoario del Género Leishmania, el cual es transmitido por el díptero hematófago vector denominado: Lutzomya sp. Hay tres formas clínicas básicas de esta enfermedad: El botón de oriente o Leishmaniasis cutánea, que es una úlcera en la piel donde picó flebotomos, la que se suele curar espontáneamente dejando una cicatriz; la leishmaniasis visceral, que es la parasitación grave del bazo, hígado y la médula ósea, que sin tratamiento conduce a la muerte; $y$ por último, la leishmaniasis monocutánea, que es la destrucción mutilante tardía de los cartílagos y mucosas del paladar blando y tabique nasal, a partir de una lesión original cutánea. Debe destacarse en el mecanismo de infección que el ciclo se amplía a la presencia de otros vectores artrópodos (varios tipos de insectos) y que algunos mamúferos silvestres (osos hormigueros, perezosos, zarigüeyas, etc.) actúan como reservorios del parásito. La terapia es efectiva en las diversas fases con el uso de drogas amoniacales. Las zonas más afectadas son las del piso ecológico rupa rupa. (1), (3), (7)

La Bartonelosis. También conocida como verruga peruana, es una enfermedad altamente endémica que solo se ha reportado en Perú, Ecuador y Colombia. Es causada por la bacteria Bartonella que es transmitido por el díptero vector hematófago del Género Lutzomya En nuestro país las zonas más afectadas son los altos valles interandinos Ancash, Lima, Cajamarca, Amazonas, Piura, La Libertad, Huancavelica, Huánuco, Cuzco, Ayacucho y Junín. (8), (9)

De donde se deduce que:

- La forma de transmisión de las enfermedades por los dípteros hematófagos se efectúa por la picadura nocturna o de madrugada del espécimen hembra de cuatro géneros: Culex, Anopheles, Aedes y Phlebotomos.

- Las hembras requieren de una dieta de sangre con la finalidad de obtener algún metabolito (quizá, adrenalina o serotonina) para fertilizar sus huevos. Según los entomólogos las antenas serían órganos sensoriales que permiten ubicar a la víctima por la emanación de $\mathrm{CO}_{2}$, sudor y temperatura corporal $u$ otros estímulos.

Las enfermedades transmitidas por dípteros más importantes en el Perú son: Leishmaniasis cutánea y monocutánea, la malaria por Plasmodium vivax y Plasmodium, el dengue clásico y la fiebre amarilla selvática. 
- Estas enfermedades infecto-contagiosas solo podrán ser controladas en nuestro país, a través del esfuerzo de equipos interdisciplinarios de profesionales que se dediquen interrumpir el ciclo biológico de los agentes infecciosos, tanto a nivel del vector díptero hematófago como a nivel del paciente humano.

\section{REFERENCIAS BIBLIOGRAFICAS:}

1. Atías, Antonio. 1999. Parasitología clínica. Sociedad médica de Santiago. Publicaciones médicas mediterráneo.

2. Beaver, P.C., Jung, R.C. y Cupp. 1990. Parasitología clínica. Salvat.

3. Botero, David. 1995. Parasitosis humanas. Bogotá. Presencia.
4. Busvine, J.R. 1992. Los insectos y la higiene. Importancia doméstica. La biología y control de insectos. Londres. Chapman y May Ltd.

5*. Miyazaki, Ichiro. 1991. Helminthic zoonoses. Tokio. International Medical Foundation of Japan.

6. Markell, K., Edward, 1996. Parasitología médica. Parasitología médica. Madrid. Interamericana.

7. Ministerio de salud. 2002. Oficina General de Epidemiología. Disponible en: http://www. Oge.sld.pe/

8. Ministerio de salud. 1999. Salud de las américas. Sistema de vigilancia epidemiológica.

9. Ministerio de salud. 2002. Perú - Disponible en: http//:www.minsa.gob.pe/programas.htm 